\title{
Experimental and bioinformatics study
} for production of $\mathrm{L}$-asparaginase from Bacillus licheniformis: a promising enzyme for medical application

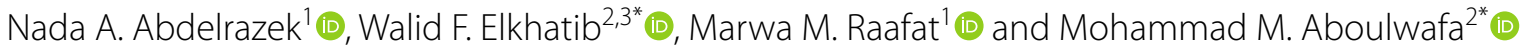

\begin{abstract}
A Bacillus licheniformis isolate with high L-asparaginase productivity was recovered upon screening two hundred soil samples. This isolate produces the two types of bacterial L-asparaginases, the intracellular type I and the extracellular type II. The catalytic activity of type II enzyme was much higher than that of type I and reached about $5.5 \mathrm{IU} / \mathrm{ml} / \mathrm{h}$. Bioinformatics analysis revealed that L-asparaginases of Bacillus licheniformis is clustered with those of Bacillus subtilis, Bacillus haloterans, Bacillus mojavensis and Bacillus tequilensis while it exhibits distant relatedness to L-asparaginases of other Bacillus subtilis species as well as to those of Bacillus amyloliquefaciens and Bacillus velezensis species. Upon comparison of Bacillus licheniformis L-asparaginase to those of the two FDA approved L-asparaginases of E. coli (marketed as Elspar) and Erwinia chrysanthemi (marketed as Erwinaze), it observed in a cluster distinct from- and with validly predicted antigenic regions number comparable to those of the two mentioned reference strains. It exhibited maximum activity at $40^{\circ} \mathrm{C}, \mathrm{pH} 8.6,40 \mathrm{mM}$ asparagine, $10 \mathrm{mM}$ zinc sulphate and could withstand $500 \mathrm{mM} \mathrm{NaCl}$ and retain $70 \%$ of its activity at $70^{\circ} \mathrm{C}$ for 30 min exposure time. Isolate enzyme productivity was improved by gamma irradiation and optimized by RSM experimental design (Box-Behnken central composite design). The optimum conditions for maximum L-asparaginase production by the improved mutant were $39.57^{\circ} \mathrm{C}, 7.39 \mathrm{pH}, 20.74 \mathrm{~h}, 196.40 \mathrm{rpm}, 0.5 \%$ glucose, $0.1 \%$ ammonium chloride, and $10 \mathrm{mM}$ magnesium sulphate. Taken together, Bacillus licheniformis L-asparaginase can be considered as a promising candidate for clinical application as antileukemic agent.
\end{abstract}

Keywords: L-Asparaginase, Bacillus licheniformis, Response surface methodology, Optimization, Characterization, Bioinformatics

\section{Introduction}

Enzymes play an important role in metabolic and biochemical reactions and microorganisms are the primary source (Nigam 2013), as they can be cultured in large quantities in short span of time (Anbu et al. 2013;

\footnotetext{
*Correspondence: walid-elkhatib@pharma.asu.edu.eg; mohamed_aboualwafa@pharm.asu.edu.eg; maboulwafa@yahoo.com ${ }^{2}$ Department of Microbiology and Immunology, Faculty of Pharmacy, Ain Shams University, African Union Organization St. Abbassia, Cairo 11566, Egypt

${ }^{3}$ Department of Microbiology and Immunology, School of Pharmacy \& Pharmaceutical Industries, Badr University in Cairo (BUC), Entertainment Area, Badr, Cairo, Egypt

Full list of author information is available at the end of the article
}

Gopinath et al. 2013). L-Asparaginase is a therapeutic enzyme which has proved to be promising for the treatment of acute lymphocytic leukemia (Sinha et al. 2013). Unlike normal cells, malignant cells can only slowly synthesize $\mathrm{L}$-asparagine, due to their deficiency in L-asparagine synthetase. Thus depletion of the circulating pools of L-asparagine by L-asparaginase leads to the destruction of the tumor cells, since they are unable to complete protein synthesis by inhibition of RNA and DNA synthesis with subsequent blastic cell apoptosis (Bansal et al. 2012). L-Asparaginase has been introduced into the pretreatment of potato slices and bread dough before frying or baking to prevent acrylamide formation (carcinogenic 
toxicant) (Krishnapura et al. 2016). Also, this enzyme acts as a biosensor to detect the amount of asparagine in leukemia and food industry (Batool et al. 2016). The current study used bioinformatics and experimental approaches for production and characterization of $\mathrm{L}$-asparaginase from the recovered soil isolate, Bacillus licheniformis. The study gives evidence for the introduction of Bacillus licheniformis L-asparaginase as a potentially comparable and additional source to those of the two FDA approved ones from E. coli (marketed under the brand name Elspar) and Erwinia chrysanthemi (marketed under the brand name Erwinaze) to be used as antileukemic agent.

\section{Materials and methods}

\section{Chemicals}

All chemicals were supplied, unless otherwise indicated, by El-Nasr chemicals ADWIC (Cairo, Egypt). L-Asparagine monohydrate was product of AppliChem $\mathrm{GmbH}$ (Darmstadt, Germany).

\section{Bacterial strain and maintenance}

Bacillus licheniformis isolate was obtained from screening of 722 soil isolates for L-asparaginase production.

\section{Isolation and qualitative detection of L-asparaginase production by recovered soil bacteria}

This was principally carried out according to Izadpanah et al. (2014). This method depends on the appearance of pink zone around L-asparaginase producing colonies on modified M9 agar medium containing $1 \% \mathrm{w} / \mathrm{v}$ asparagine and phenol red as an indicator.

\section{Inoculum preparation and L-asparaginase production}

The inoculum was prepared by inoculating $20 \mathrm{ml}$ modified M9 broth contained in $250 \mathrm{ml}$ Erlenmeyer flask with single isolated colony. The flask was incubated at $37{ }^{\circ} \mathrm{C}$ and $180 \mathrm{rpm}$ for $24 \mathrm{~h}$. The broth culture obtained was diluted by fresh M9 broth medium to an O.D. $=1.0$ at $600 \mathrm{~nm}$ to be used as an inoculum. The enzyme production was carried out in $250 \mathrm{ml}$ Erlenmeyer flasks, the flasks were inoculated with $2 \% \mathrm{v} / \mathrm{v}$ from the cell suspension (Mahajan et al. 2012) and incubated at $37^{\circ} \mathrm{C}$ and $180 \mathrm{rpm}$ for $24 \mathrm{~h}$. An aliquot $(2 \mathrm{ml})$ of the broth culture obtained was centrifuged at $4{ }^{\circ} \mathrm{C}$ and $5000 \mathrm{rpm}$ for $20 \mathrm{~min}$ using cooling centrifuge (Jain et al. 2012). The produced supernatant was termed crude enzyme preparation and used for quantitative assay of extracellular L-asparaginase while the produced pellets were lysed and tested for any intracellular enzyme activity. For the preparation of crude cell lysate, the cell pellets were washed twice with $50 \mathrm{mM}$ Tris- $\mathrm{HCl}(\mathrm{pH} 7.5)$ and suspended in $30 \mathrm{ml}$ lysis buffer (Straight et al. 2007). Cells were then disrupted by sonication using sonication probe under cooling condition at
$4{ }^{\circ} \mathrm{C}$. Cellular debris and unbroken cells were removed by centrifugation at $15,000 \mathrm{rpm}$ and $4{ }^{\circ} \mathrm{C}$ for $15 \mathrm{~min}$ (Sakr et al. 2014) and the supernatant was collected for determination of intracellular enzyme activity.

\section{Quantitative assay of L-asparaginase}

L-Asparaginase activity was measured by the method described by of Mashburn and Wriston (1963). The assay depends on hydrolysis of L-asparagine by the enzyme preparation to release ammonia. One unit of L-asparaginase activity is defined as the amount of enzyme required for the release of one micromole of ammonia per hour at $37^{\circ} \mathrm{C}$ and $\mathrm{pH}$ 8.6 (Mahajan et al. 2014).

\section{Identification of soil isolate with highest L-asparaginase productivity}

The isolate of the highest $\mathrm{L}$-asparaginase productivity was identified by microscopical examination (Gram stain), biochemical reactions (using Biolog ${ }^{\circledR}$ system) and confirmed by the $16 \mathrm{~S}$ rRNA gene sequencing.

\section{Bioinformatics analysis}

The degrees of relatedness of Bacillus licheniformis $\mathrm{L}$-asparaginase to other microbial $\mathrm{L}$-asparaginases (the amino acid sequence of the enzyme of that organism was used as a probe to retrieve NCBI database similar sequences in BLAST) and to the two FDA approved L-asparaginases of $E$. coli (marketed under the brand name Elspar) and Erwinia chrysanthemi (marketed under the brand name Erwinaze) were inferred by the Maximum Likelihood method based on the JTT matrix-based model (Jones et al. 1992) using their amino acid sequences. The phylogenetic tree was drawn to scale, with branch lengths measured in the number of substitutions per site. Evolutionary analyses were conducted in MEGA X (Kumar et al. 2018). The antigenic sites in Bacillus licheniformis L-asparaginase as compared to those in the two FDA approved L-asparaginases of E. coli and Erwinia chrysanthemi were predicted using the method of Kolaskar and Tongaonkar (1990) (EMBOSS: antigenic-Bioinformatics web site http://www.bioinformatics.nl/cgi-bin/emboss/antigenic).

\section{L-Asparaginase characterization}

The crude preparation of L-asparaginase (supernatant of growth culture) of the selected isolate was evaluated for different characteristics of industrial importance which included thermal stability, activity at different temperatures, $\mathrm{pH}$ values, salinities, substrate concentrations, and metal ions. 
Improvement of L-asparaginase production of the selected isolate by mutation with gamma irradiation

Five $\mathrm{ml}$ aliquot of a prepared spore suspension (Seale et al. 2008), contained in $10 \mathrm{ml}$ sterile screw capped glass tubes, was exposed to different doses of gamma rays 0.1, 0.5, 1, 3, and $5 \mathrm{KGy}$ (Diep et al. 2017). After irradiation, a number of recovered colonies were selected randomly to be qualitatively and quantitatively assessed for L-asparaginase production in comparison to the parent wild strain. The mutant with the highest L-asparaginase productivity was selected for completing the present study.

\section{Effect of different environmental and physiological factors influencing L-asparaginase production by the selected mutant}

Different environmental factors including incubation temperature, initial $\mathrm{pH}$, incubation time, agitation rate as well as various media components were evaluated for their effects on $\mathrm{L}$-asparaginase production. In all cases, at the end of the incubation period L-asparaginase activity was quantitatively determined as described before except that in case of studying the effect of incubation time where samples were removed at different time intervals for $\mathrm{L}$-asparaginase activity measurements.

\section{Optimization of L-asparaginase production using response surface methodology (RSM) experimental design}

From preliminary conducted studies, four process parameters [incubation temperature coded (A), $\mathrm{pH}$ values coded (B), incubation time coded (C) and agitation rate coded (D)] were optimized by RSM experimental design (Box-Behnken central composite design). Each parameter was examined at 3 levels that correspond to the 3 highest L-asparaginase productivity obtained. The mean level of each parameter was coded (0) and it represents the average of the 2 levels that showed the highest and the lowest $\mathrm{L}$-asparaginase production. The maximum level coded $(+1)$ and the lower level coded $(-1)$. The range of studied variables is shown in Additional file 1: Table S1. Design-Expert 7 (Stat-Ease Inc., Minneapolis, MN, USA) was used for experimental design as well as graphical analyses of the data and regressions. A number of 27 experiments were obtained. The codes and values of the three levels for the studied variables $(n=4)$ are shown in Additional file 1: Table S2. These experiments were principally carried out as mentioned before, except that the environmental conditions (incubation temperature, initial $\mathrm{pH}$, incubation time, agitation) were set at the values listed in Additional file 1: Table S2. The results obtained from the 27 experiments were analyzed by the used software to determine the response surface contour plots, the regression equation and the test variables optimum levels.

\section{Effect of different media components}

The effect of different carbon sources (glucose, sucrose, fructose, lactose, maltose, glycerol, starch and arabinose), nitrogen sources (ammonium chloride, potassium nitrate, ammonium nitrate, yeast extract, peptone, urea, tryptone) and metal ions (copper sulphate, calcium chloride dihydrate, magnesium sulphate heptahydrate, cobalt chloride, manganese sulphate zinc sulphate heptahydrate) were evaluated for their effects on L-asparaginase production by the test mutant. Each of the carbon source, the nitrogen source and the metal ion source that showed maximum L-asparaginase productivity was re-tested at different concentrations.

\section{Statistical and graphical analyses}

All experiments were carried out in triplicates and the mean as well as standard deviation were calculated. The data were statistically analyzed using one way ANOVA followed by Dunnett's Multiple Comparison Test. All tests were performed using Graph Pad Prism Version 5.0 (GraphPad Software, La Jolla, CA, USA).

\section{Results}

Recovery and identification of a promising L-asparaginase producing isolate

A promising $\mathrm{L}$-asparaginase-producing bacterial isolate was selected using an extensive screening program on 722 recovered bacterial soil isolates. This isolate was identified using the methods listed in materials and methods as Bacillus licheniformis and its 16S rRNA gene sequence was deposited in GenBank database under the accession number MG665995, the strain also deposited in Egypt Microbiological Culture collection (EMCC) with number EMCC 2290. The extracellular L-asparaginase productivity of this test isolate exceeded the intracellular one by at least threefolds (data not shown). Accordingly, L-asparaginase characterization and production optimization were based on the extracellular enzyme productivity.

\section{Bioinformatics analysis}

The molecular phylogenetic tree of L-asparaginases with amino acids sequence similarities not less than $74 \%$ to the target query L-asparaginase of Bacillus licheniformis is shown in Fig. 1 while that of the target query L-asparaginase and the two FDA approved L-asparaginases of E. coli (marketed under the brand name Elspar) and Erwinia chrysanthemi (marketed under the brand name Erwinaze) is shown in Fig. 2. The corresponding pairwise distances among L-asparaginases for bacterial species presented in Fig. 1 is shown in Table (S3) while those for L-asparaginases of bacterial species presented in Fig. 2 is illustrated in 


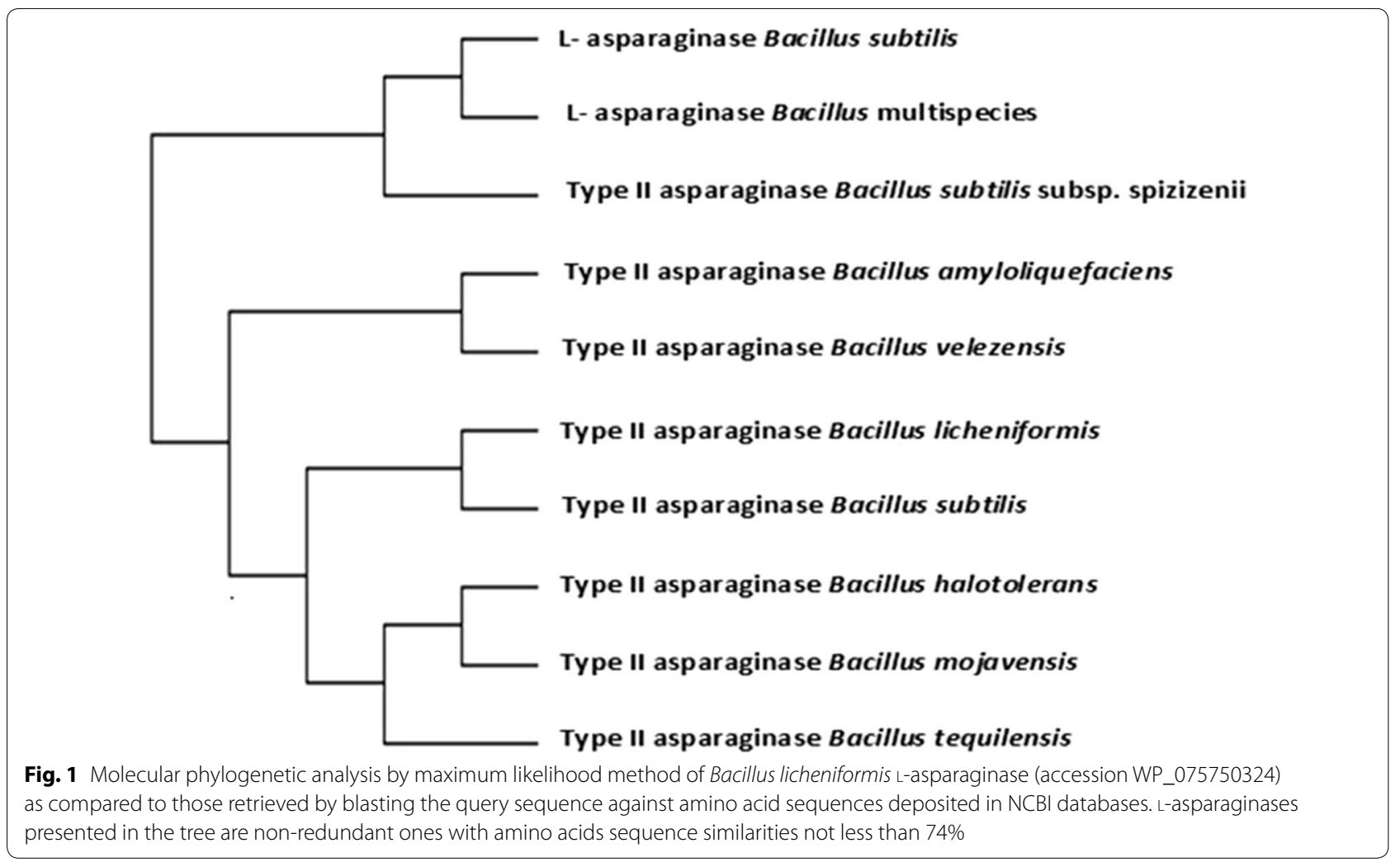

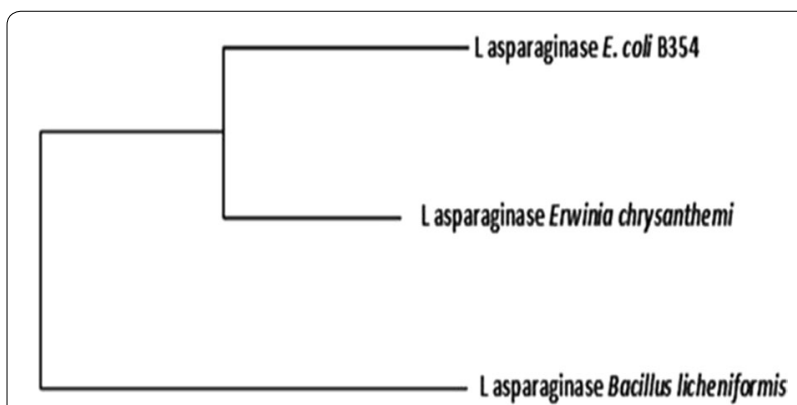

Fig. 2 Molecular phylogenetic analysis by maximum likelihood method of Bacillus licheniformis L-asparaginase (accession WP_075750324) when blasted against amino acid sequences of the FDA approved L-asparaginases of E. coli and Erwinia chrysanthemi

Additional file 1: Table S4. Potentially antigenic regions of a L-asparaginase sequence of Bacillus licheniformis were predicted and compared to those determined for E. coli and Erwinia chrysanthemi using the prediction program EMBOSS antigenic explorer ${ }^{\circledR}$ as mentioned in Materials and Methods. The results presented in Table 1 reveal 18, 16 and 17 antigenic regions, their positions and sequences for L-asparaginases of $E$. coli, Erwinia chrysanthemi and Bacillus licheniformis, respectively.

\section{L-Asparaginase characterization of the test isolate}

The results (Fig. 3) revealed that L-asparaginase activity was not dramatically affected when exposed to temperature up to $50{ }^{\circ} \mathrm{C}$ for $30 \mathrm{~min}$, and the maximal activity was observed at $40{ }^{\circ} \mathrm{C}$, pH 8.6 and $40 \mathrm{mM}$ asparagine concentration. The enzyme activity increased by incorporation of sodium chloride up to $100 \mathrm{mM}$ and the enzyme could efficiently retain its activity at high salinity up to $500 \mathrm{mM}$ sodium chloride. From the tested metal salts (copper sulphate, nickel chloride, cobalt chloride, ferrous sulphate and zinc sulphate), zinc sulphate was the only metal salt that showed significant $(p<0.05)$ increase in enzyme activity. Other tested metal salts showed no significant effect as compared to the control.

\section{Strain improvement}

Gamma irradiation was utilized to improve L-asparaginase production by the test isolate. The results revealed that exposure to $5 \mathrm{KGy}$ gamma radiations enabled the 


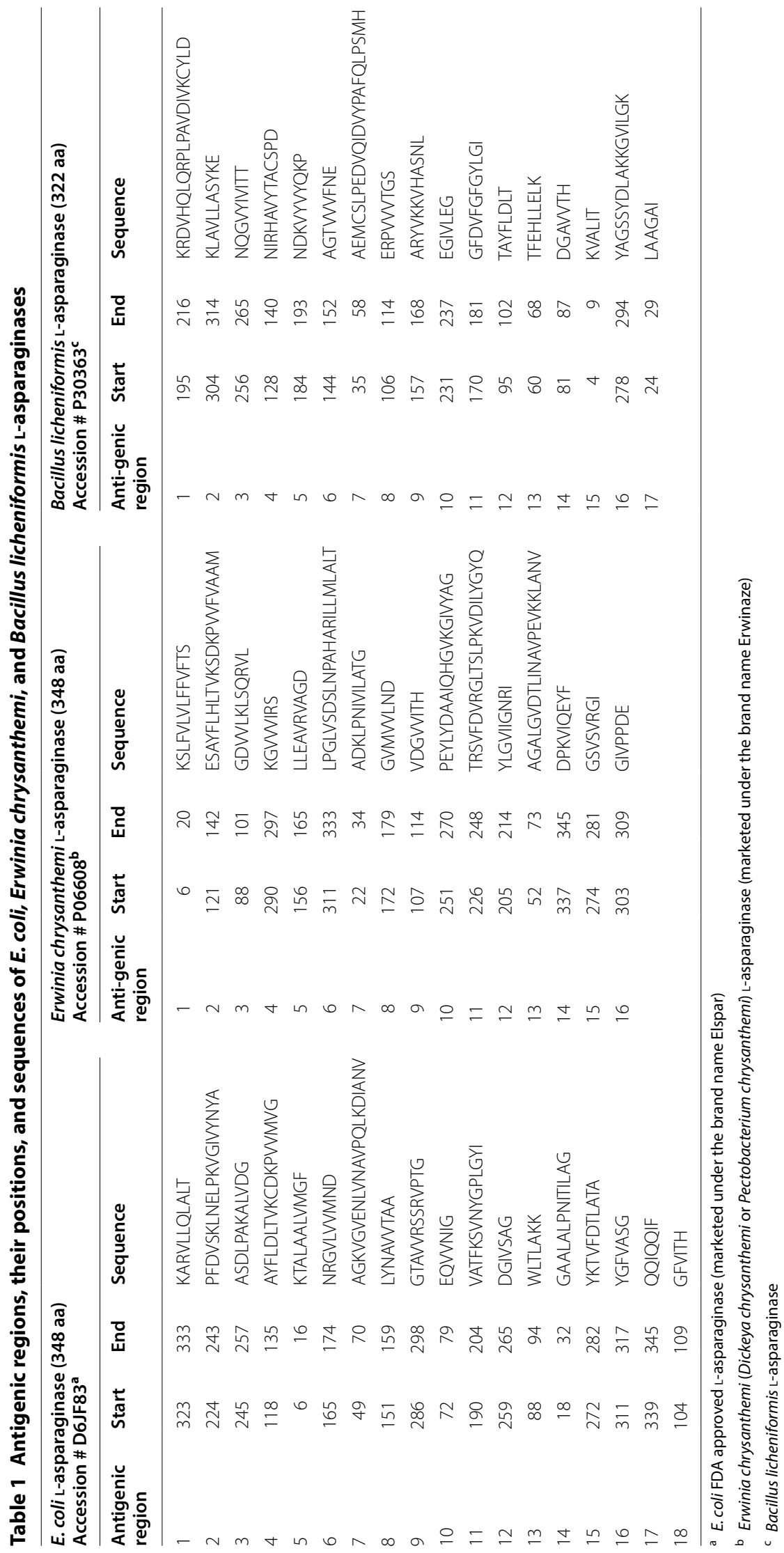



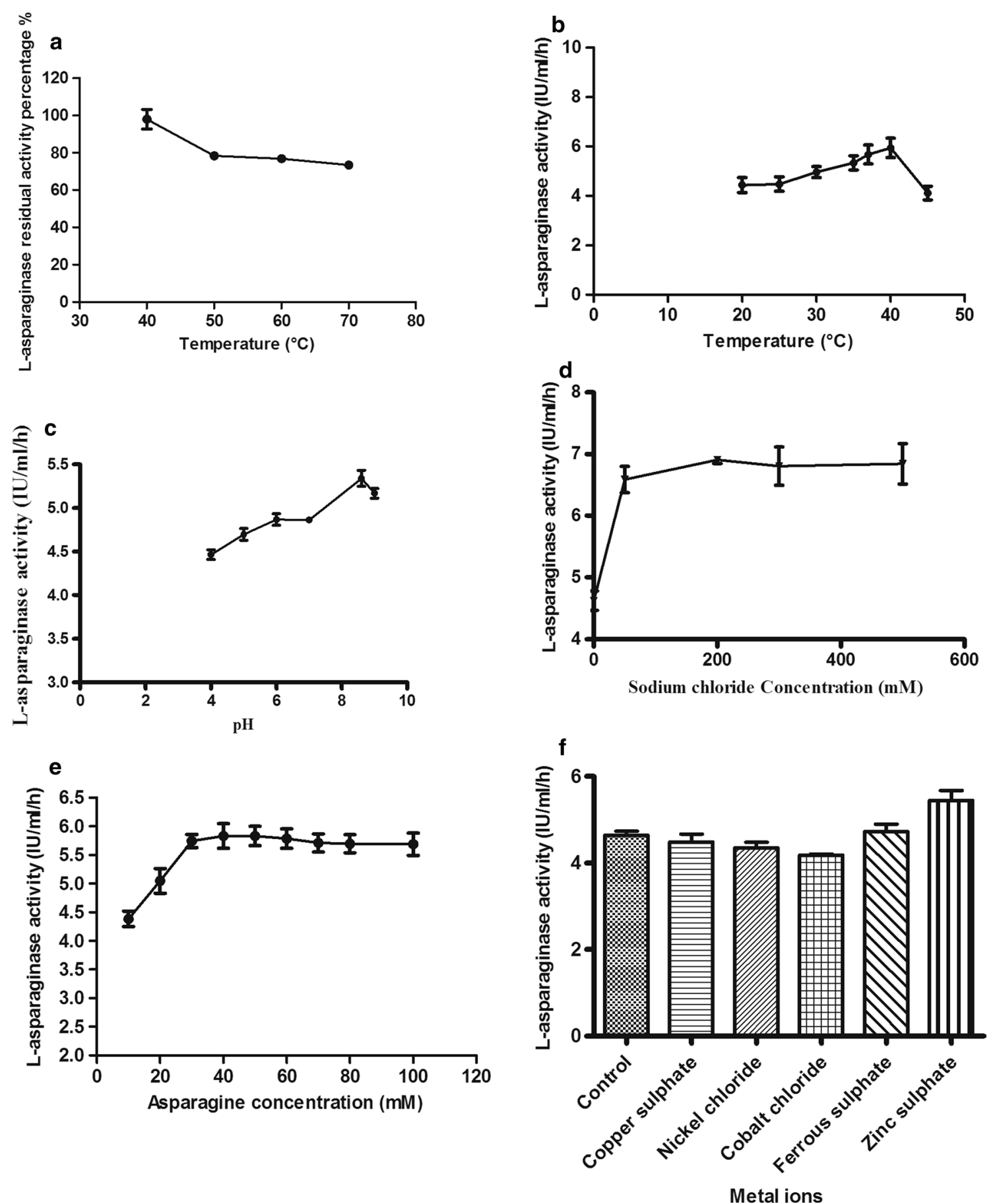

Fig. 3 Thermal stability (a) and catalytic activities at different temperatures (b), pH values (c), salinities (d), substrate concentrations (e) and metal ions (f) of L-asparaginase produced by Bacillus licheniformis

selection of a mutant with higher L-asparaginase productivity compared to the lower tested doses of gamma radiations (data not shown). The enzyme productivity of the selected mutant was 1.4 fold higher than that of the parent strain.
Model-based optimization of L-asparaginase production by Bacillus licheniformis mutant

Effect of environmental conditions and RSM experimental design

Regarding the effect of incubation temperature, it was found that low level of $\mathrm{L}$-asparaginase production by 
Bacillus licheniformis mutant occurs at $20{ }^{\circ} \mathrm{C}$, reached its maximum level at $37{ }^{\circ} \mathrm{C}$ and slightly decreased thereafter up to $50{ }^{\circ} \mathrm{C}$. Concerning the effect of initial $\mathrm{pH}$, there was a considerable L-asparaginase production at all the tested $\mathrm{pH}$ values with a maximum productivity achieved at $\mathrm{pH} 7$. Regarding the effect of incubation time, the results revealed that the maximum $\mathrm{L}$-asparaginase production by the test mutant is attained at $24 \mathrm{~h}$ followed by gradual decrease in the production. In case of agitation rate, the maximum $\mathrm{L}$-asparaginase productivity was obtained at $180 \mathrm{rpm}$ and lower productivities at agitation rates around this value were noted (Fig. 4). RSM experimental design was applied on pretested environmental parameters (four variables) which included incubation temperature, initial $\mathrm{pH}$, incubation time and agitation rate. The results of the response surface model including observed, predicted, residual values are given in Table 2. According to the mathematical model regression equation, the predicted values were calculated as follows:

$$
\begin{aligned}
& \text { Sqrt } \\
& \begin{aligned}
(\text { l-asparaginase activity) } & +2.68+0.014 * \mathrm{~A}+0.056 * \mathrm{~B}-0.14 * \mathrm{C}+0.024 * \mathrm{D} \\
& -2.127 \mathrm{E}-004 * \mathrm{~A} * \mathrm{~B}+0.013 * \mathrm{~A} * \mathrm{C}+0.033 * \mathrm{~A} * \mathrm{D} \\
& -0.013 * \mathrm{~B} * \mathrm{C}+0.017 * \mathrm{~B} * \mathrm{D}+0.017 * \mathrm{C} * \mathrm{D} \\
& -2.410 \mathrm{E}-004 * \mathrm{~A}^{2}-0.100 * \mathrm{~B}^{2}-0.017 * \mathrm{C}^{2}-0.018 * \mathrm{D}^{2}
\end{aligned}
\end{aligned}
$$

where L-asparaginase activity was expressed in square root values, and A, B, C and D represent incubation temperature, initial $\mathrm{pH}$ value, incubation time and agitation rate, respectively.

Additional file 1: Table S5 shows ANOVA of the obtained quadratic model. Model F-value of 19.59 implies that the model is significant. For the obtained F-value, a p-value less than 0.0001 means that there is only $0.01 \%$ chance that this large model F-value could occur due to noise. The regression coefficient of the model $\left(R^{2}\right)$ was evaluated to test the fit of the model. The $\mathrm{R}^{2}$ was calculated to be 0.9581 , referring that the model could explain $95.81 \%$ of the variability. Only $4.19 \%$ of the total variation is not explained by the model. The "Predicted R-Squared" of 0.7600 is in reasonable agreement (a difference not exceeding the recommended value of 0.3 with the "Adjusted R-Squared" of 0.9092 (Frost 2013).

The adequate precision measures the signal (response) to noise ratio. It is desirable that the ratio to be greater than 4 . A ratio 15.913 indicates an adequate signal to noise ratio. Therefore this model can be used to navigate the design space. The "lack of fit" used to compare the residual error to the "pure error" from
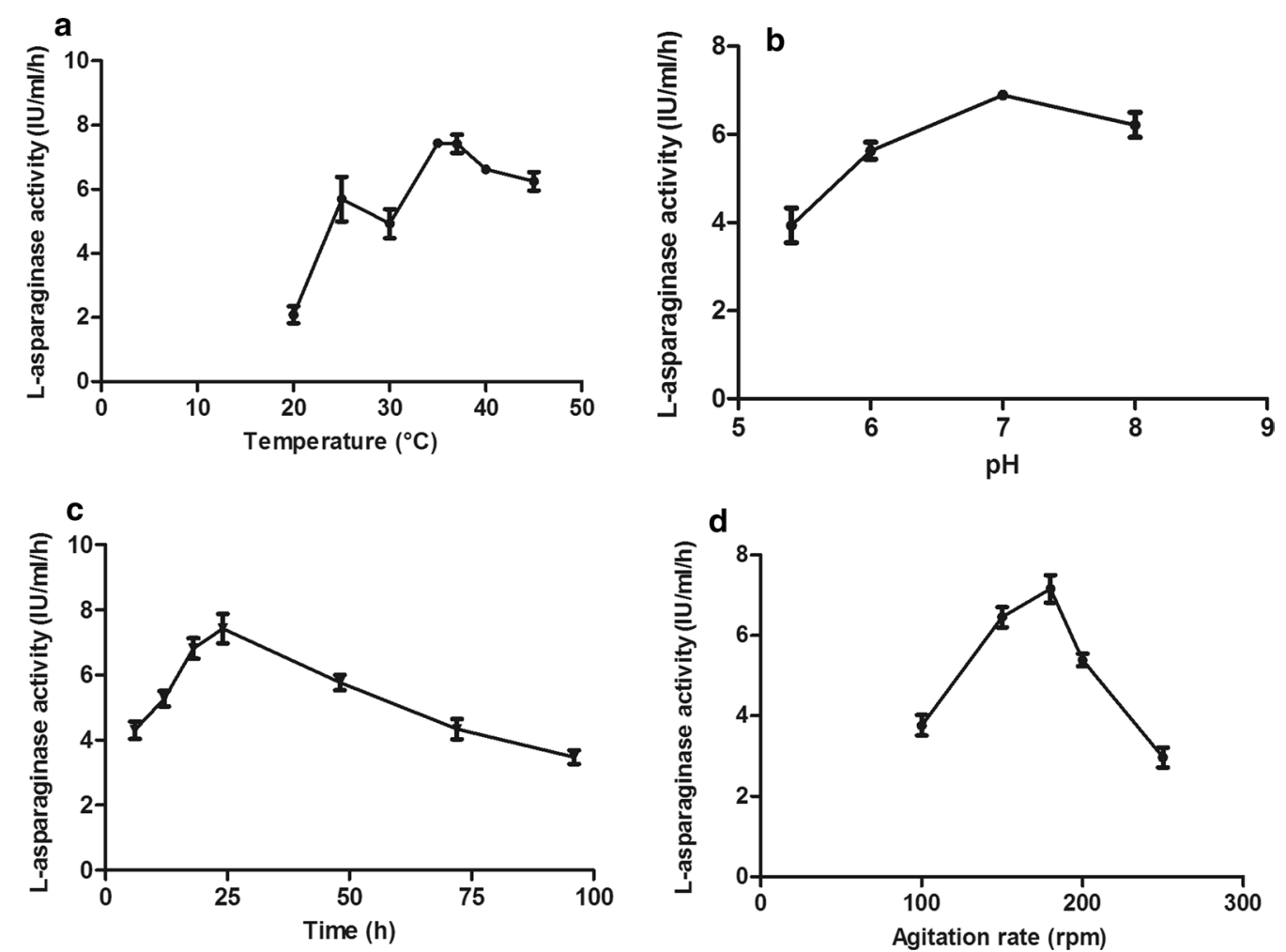

Fig. 4 Effect of incubation temperature (a), initial pH (b), incubation time (c), and agitation rate (d) on L-asparaginase production by Bacillus licheniformis mutant. The enzyme productivity was expressed in terms of catalytic activity 
Table 2 Observed, predicted, and residual values for process parameters optimization of L-asparaginase productivity by Bacillus licheniformis mutant using Box-Behnken central composite design

\begin{tabular}{|c|c|c|c|c|c|c|c|}
\hline \multirow[t]{2}{*}{ Experiment } & \multirow[t]{2}{*}{ Temperature $\left({ }^{\circ} \mathrm{C}\right)$} & \multirow[t]{2}{*}{$\mathrm{pH}$} & \multirow[t]{2}{*}{ Time (h) } & \multirow[t]{2}{*}{ Agitation (rpm) } & \multicolumn{2}{|c|}{$\begin{array}{l}\text { Square root of L-asparaginase activity (IU/ } \\
\mathrm{ml} / \mathrm{h} \text { ) }\end{array}$} & \multirow[t]{2}{*}{ Residual value } \\
\hline & & & & & Observed value & Predicted value & \\
\hline 1 & 35 & 6 & 33 & 175 & 2.52 & 2.51 & 0.01 \\
\hline 2 & 40 & 6 & 33 & 175 & 2.49 & 2.54 & -0.05 \\
\hline 3 & 35 & 8 & 33 & 175 & 2.67 & 2.63 & 0.04 \\
\hline 4 & 40 & 8 & 33 & 175 & 2.64 & 2.65 & -0.01 \\
\hline 5 & 37.5 & 7 & 18 & 150 & 2.76 & 2.78 & -0.02 \\
\hline 6 & 37.5 & 7 & 48 & 150 & 2.45 & 2.47 & -0.02 \\
\hline 7 & 37.5 & 7 & 18 & 200 & 2.81 & 2.79 & 0.02 \\
\hline 8 & 37.5 & 7 & 48 & 200 & 2.56 & 2.55 & 0.01 \\
\hline 9 & 35 & 7 & 33 & 150 & 2.66 & 2.66 & 0 \\
\hline 10 & 40 & 7 & 33 & 150 & 2.65 & 2.62 & 0.03 \\
\hline 11 & 35 & 7 & 33 & 200 & 2.61 & 2.64 & -0.03 \\
\hline 12 & 40 & 7 & 33 & 200 & 2.74 & 2.74 & 0 \\
\hline 13 & 37.5 & 6 & 18 & 175 & 2.65 & 2.62 & 0.03 \\
\hline 14 & 37.5 & 8 & 18 & 175 & 2.79 & 2.77 & 0.02 \\
\hline 15 & 37.5 & 6 & 48 & 175 & 2.37 & 2.39 & -0.02 \\
\hline 16 & 37.5 & 8 & 48 & 175 & 2.46 & 2.47 & -0.01 \\
\hline 17 & 35 & 7 & 18 & 175 & 2.76 & 2.8 & -0.04 \\
\hline 18 & 40 & 7 & 18 & 175 & 2.8 & 2.8 & 0 \\
\hline 19 & 35 & 7 & 48 & 175 & 2.52 & 2.5 & 0.02 \\
\hline 20 & 40 & 7 & 48 & 175 & 2.6 & 2.56 & 0.04 \\
\hline 21 & 37.5 & 6 & 33 & 150 & 2.53 & 2.5 & 0.03 \\
\hline 22 & 37.5 & 8 & 33 & 150 & 2.57 & 2.58 & -0.01 \\
\hline 23 & 37.5 & 6 & 33 & 200 & 2.54 & 2.52 & 0.02 \\
\hline 24 & 37.5 & 8 & 33 & 200 & 2.65 & 2.66 & -0.01 \\
\hline $25^{*}$ & 37.5 & 7 & 33 & 175 & 2.67 & 2.68 & -0.01 \\
\hline $26^{*}$ & 37.5 & 7 & 33 & 175 & 2.69 & 2.68 & 0.01 \\
\hline $27^{*}$ & 37.5 & 7 & 33 & 175 & 2.68 & 2.68 & 0 \\
\hline
\end{tabular}

* The 3 replicates at the center point of the tested values ( $\mathrm{pH}$, temperature, time, agitation)

replicated design points. The "lack of fit F-value" of 19.2 implies that the lack of fit is not significant relative to the pure error. Non-significant lack of fit indicates the model fits. As the magnitude of F-value became larger and the magnitude of $p$ value smaller, the corresponding coefficient is more significant (Adinarayana and Ellaiah 2002). Table 3 lists the process parameters that proved to be significant for L-asparaginase productivity.

\section{Graphical representation of dual interactions of process parameters}

The 3D response surface and 2D contour plots (Figs. 5, 6) are the graphical representations of the regression equation. Response surface plots [RSPs] (a) and (b) show the effect of temperature and its interactions with $\mathrm{pH}$ and agitation, respectively. The interactions reveal the predicted maximum $\mathrm{L}$-asparaginase productivity of
Table 3 Process parameters having significant effects on L-asparaginase productivity by Bacillus licheniformis shown in descending order of significance

\begin{tabular}{ll}
\hline Order & Process parameter factor \\
\hline 1 & Incubation time \\
2 & Square term of initial pH \\
3 & Initial pH \\
4 & Agitation rate \\
\hline
\end{tabular}

$7.30761 \mathrm{IU} / \mathrm{ml} / \mathrm{h}$ at $\mathrm{pH} 7.19$ and temperature $39.99{ }^{\circ} \mathrm{C}$ and $7.48121 \mathrm{IU} / \mathrm{ml} / \mathrm{h}$ at the same temperature $\left(39.99^{\circ} \mathrm{C}\right)$ $200 \mathrm{rpm}$. On the other hand, RSPs (c) and (d) demonstrate the effect of $\mathrm{pH}$ and its interactions with agitation and incubation time, respectively. The interactions show 
a

Design-Expert@ Software

Original Scale

Sort(L-Asparaginase activity)

5.5984 $\mathrm{X} 2=\mathrm{B}: \mathrm{pH}$

Actual Factors

C: Time $=33.00$

D: Agitation $=175.00$

b

\section{Design-Expert( Software Original Scale \\ Sqrt(L-Asparaginase activity) \\ 7.87728 \\ 5.5984}

$\mathrm{X} 1=\mathrm{A}:$ Temperature

$\mathrm{X} 2$ = D: Agitation

Actual Factors

B: $\mathrm{pH}=7.00$

C. Time $=33.00$

C

Design-Expert(®) Software Original Scale

7.87728

5.5984

$\mathrm{X} 1=\mathrm{B}: \mathrm{pH}$

$\mathrm{X} 2=\mathrm{D} \cdot$ Agitation

Actual Factors

A: Temperature $=37.50$

C: Time $=33.00$
$\mathrm{X} 1=\mathrm{A}:$ Temperature

Sqrt(L-Asparaginase activity)
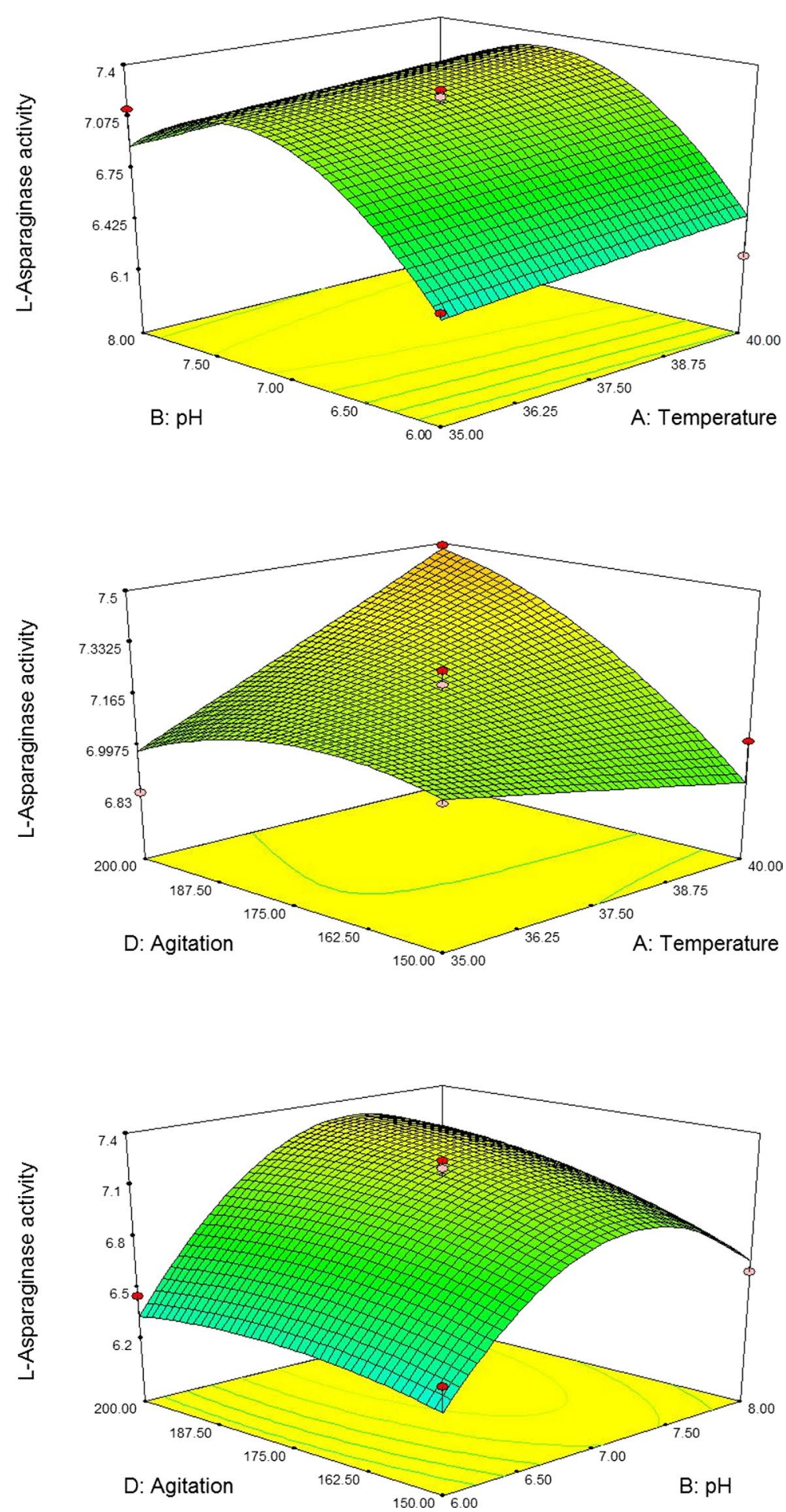

Fig. 5 Response surface plots for the optimization of process parameters showing the effect of a the interaction between temperature $\left({ }^{\circ} \mathrm{C}\right)$ and $\mathrm{pH}$ b the interaction between temperature $\left({ }^{\circ} \mathrm{C}\right)$ and agitation ( $\mathrm{rpm}$ ); $\mathbf{c}$ the interaction between $\mathrm{pH}$ and agitation ( $\mathrm{rpm}$ ) on L-asparaginase production by Bacillus licheniformis mutant strain. The enzyme productivity was expressed in terms of catalytic activity 


\section{a}

Design-Expertæ Software

Original Scale

Sqrt(L-Asparaginase activity)

7.87728

5.5984

$\mathrm{X} 1=\mathrm{B}: \mathrm{pH}$

$\mathrm{X} 2=\mathrm{C}:$ Time

Actual Factors

A. Temperature $=37.50$

D: Agitation $=175.00$

b

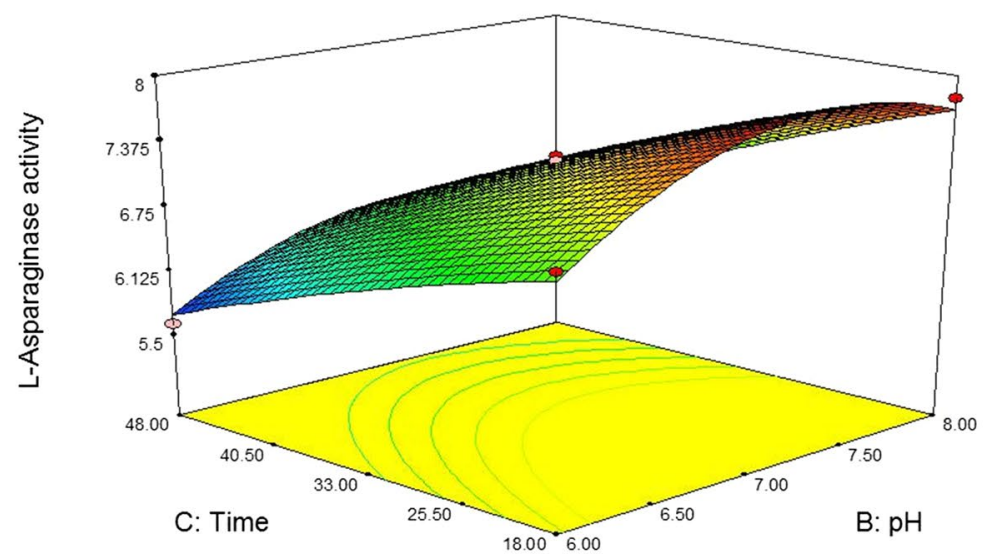

Design-Expert@ Software Original Scale

Sqrt(L-Asparaginase activity)

7.87728

5.5984

X1 = C: Time

$\mathrm{X} 2$ = A: Temperature

Actual Factors

B: $\mathrm{pH}=7.00$

D: Agitation $=17500$

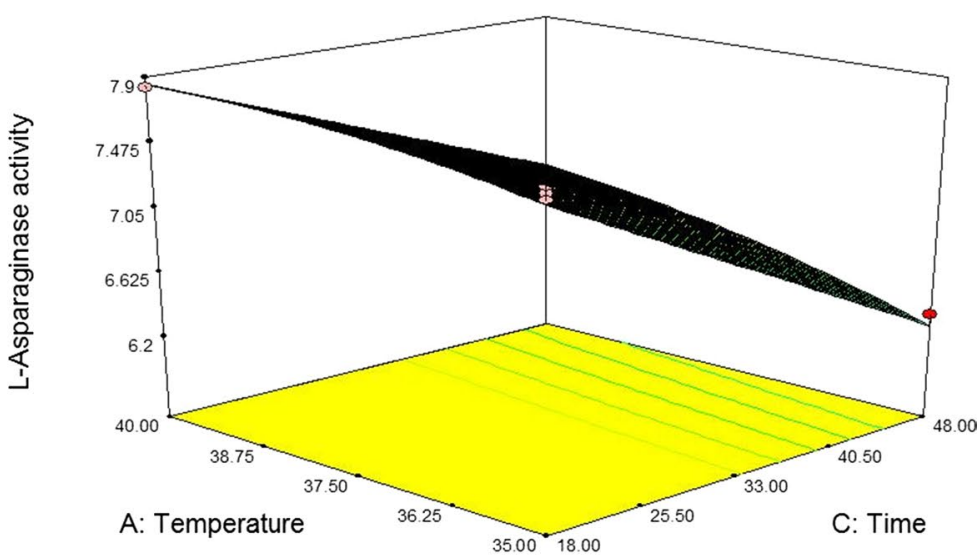

C

Design-Expert® Software Original Scale

Sart(L-Asparaginase activity)

78772

5.5984

X1 = C: Time

X2 = D: Agitation

Actual Factors

A: Temperature $=37.50$

B. $\mathrm{pH}=7.00$

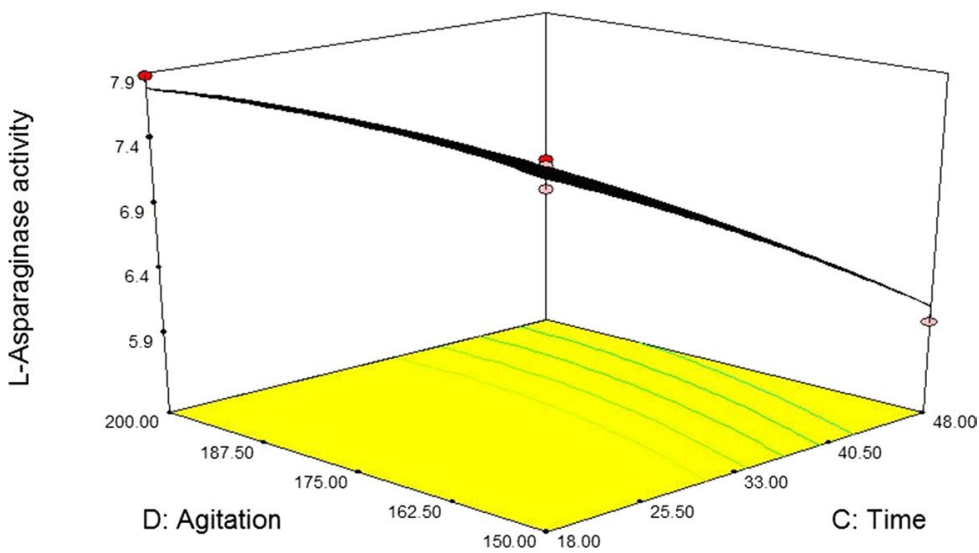

Fig. 6 Response surface plots for the optimization of process parameters showing the effect of $\mathbf{a}$ the interaction between $\mathrm{pH}$ and time (h); $\mathbf{b}$ the interaction between time $(h)$ and temperature $\left({ }^{\circ} \mathrm{C}\right)$; and $\mathbf{c}$ the interaction between time $(h)$ and agitation $(\mathrm{rpm})$ on L-asparaginase production by Bacillus licheniformis mutant strain. The enzyme productivity was expressed in terms of catalytic activity 
the predicted maximum $\mathrm{L}$-asparaginase productivity of $7.3004 \mathrm{IU} / \mathrm{ml} / \mathrm{h}$ at $\mathrm{pH} 7.35$ and agitation $199.95 \mathrm{rpm}$ and $7.90794 \mathrm{IU} / \mathrm{ml} / \mathrm{h}$ at $\mathrm{pH} 7.46$ and $18.01 \mathrm{~h}$. RSPs (e) and (f) represent the effect of incubation time and its interactions with temperature and agitation rate, respectively. Their interactions also predict maximum $\mathrm{L}$-asparaginase productivity of $7.85147 \mathrm{IU} / \mathrm{ml} / \mathrm{h}$ at temperature $40{ }^{\circ} \mathrm{C}$ and time $18 \mathrm{~h}$ and of $7.8464 \mathrm{IU} / \mathrm{ml} / \mathrm{h}$ at the same incubation time $(18 \mathrm{~h})$ and $184.44 \mathrm{rpm}$.

The main objective of applying response surface methodology is to specify the optimum value of each variable to maximize the studied response. According to the applied model, the predicted maximum value of L-asparaginase productivity of Bacillus licheniformis is $7.9518 \mathrm{IU} / \mathrm{ml} / \mathrm{h}$ and it can be obtained at temperature of $39.5^{\circ} \mathrm{C}, \mathrm{pH}$ of 7.4 , incubation time of $21 \mathrm{~h}$, and agitation rate of $196 \mathrm{rpm}$.

\section{Effect of media components}

By studying the effect of different carbon sources (glucose, sucrose, fructose, lactose, maltose, glycerol, starch and arabinose), glucose proved to be the best carbon source for L-asparaginase production. Regarding the nitrogen sources, ammonium chloride showed the highest enzyme production. Furthermore, incorporation of different metal ions into the culture medium revealed that the highest enzyme productivity occurred with magnesium sulphate. Based on the obtained results, different concentrations of the best carbon and nitrogen sources as well as metal ions for L-asparaginase production were tested. Concentrations of $0.5 \% \mathrm{w} / \mathrm{v}$ glucose, $0.1 \% \mathrm{w} / \mathrm{v}$ ammonium chloride and $10 \mathrm{mM}$ magnesium sulphate were noted to be the optimum concentrations for maximum L-asparaginase production (Fig. 7).

\section{Discussion}

L-Asparaginase has received considerable attention as a primary component in the treatment of acute lymphoblastic leukemia (ALL) (Rati Sinha et al. 2013). Extracellular enzymes have an advantage over the intracellular ones; they could be produced plentifully in the culture medium under normal conditions and could be purified economically (Joseph and Rajan 2011; Vaibhav D Deokar et al. 2010). In this study the extracellular activity was about 305\% more than the intracellular one, this offers easy enzyme recovery without the need for cell lysis.

It is reported that bacterial type L-asparaginases are classified into subtypes I and II, which is defined by their intra or extra cellular localization (Michalska and Jaskolski 2006). Type I (cytosolic) has a lower affinity for L-asparagine, while type II (periplasmic) has a high substrate affinity and they also differ in oligomeric form. The periplasmic proteins, known as type II asparaginases (Campbell and Mashburn 1969), from Escherichia coli (EcAII) and Erwinia chrysanthemi (ErA), have been in clinical use in the treatment of acute lymphoblastic leukemia and some other tumors for more than 30 years (Roberts et al. 1966; Boyse et al. 1967; Bodey et al. 1974; Lay et al. 1975). Accordingly, the present study was focused on extracellular enzyme productivity of the used bacterial isolate. The phylogenetic tree shown in Fig. 1 and Table 3 shows that L-asparaginases of Bacillus licheniformis is clustered with those of Bacillus subtilis (pairwise distance 0.00267), Bacillus haloterans (pairwise distance 0.1128), Bacillus mojavensis (pairwise distance 0.11579) and Bacillus tequilensis (pairwise distance 0.0892) while it shows distant relatedness to L-asparaginases of other Bacillus subtilis species (pairwise distance 2.07678) as well as for those of Bacillus amyloliquefaciens and Bacillus velezensis species (pairwise distances 2.13201 for each). Figure 2 and Additional file 1: Table S4 show the situation of $\mathrm{L}$-asparaginase for Bacillus licheniformis to those of the two FDA approved L-asparaginases of E. coli (marketed under the brand name Elspar) and Erwinia chrysanthemi (marketed under the brand name Erwinaze), both were used as two reference enzymes. The results reveal that occurrence of Bacillus licheniformis L-asparaginase is a cluster distinct from those of the two other reference enzymes (Fig. 2) and a pairwise distances of 1.253 and 1.161 for L-asparaginases of E. coli and Erwinia chrysanthemi, respectively (Additional file 1: Table S4). Prediction of antigenic determinants (epitopes) along the amino acid sequences of the corresponding L-asparaginases of E. coli, Erwinia chrysanthemi (as two reference strains for FDA approved L-asparaginases) and Bacillus licheniformis showed in between antigenic regions number for Bacillus licheniformis. The validity of this prediction is supported by the observation that Erwinia asparaginase has less immunogenic associated toxicity as compared to that of $E$. coli asparaginase (Barry et al. 2007). Also Cavanna et al. (1976) reported that L-asparaginase from $E$. coli has more immuno-depressive and immuno-toxic potential than that from $E$. carotovora. The therapeutic effect of $\mathrm{L}$-asparaginases from these two bacterial species (E. coli and Erwinia) is accompanied by side effects which are partially attributed to the immunogenicity of these enzymes. Comparable number of antigenic regions detected in L-asparaginase of Bacillus licheniformis suggests fewer side effects and this could introduce such enzyme source as a potential candidate for therapeutic and medical application.

Regarding enzyme thermal stability, a remarkable stability was demonstrated as the produced enzyme could preserve $80 \%$ of its activity after exposure to temperature 

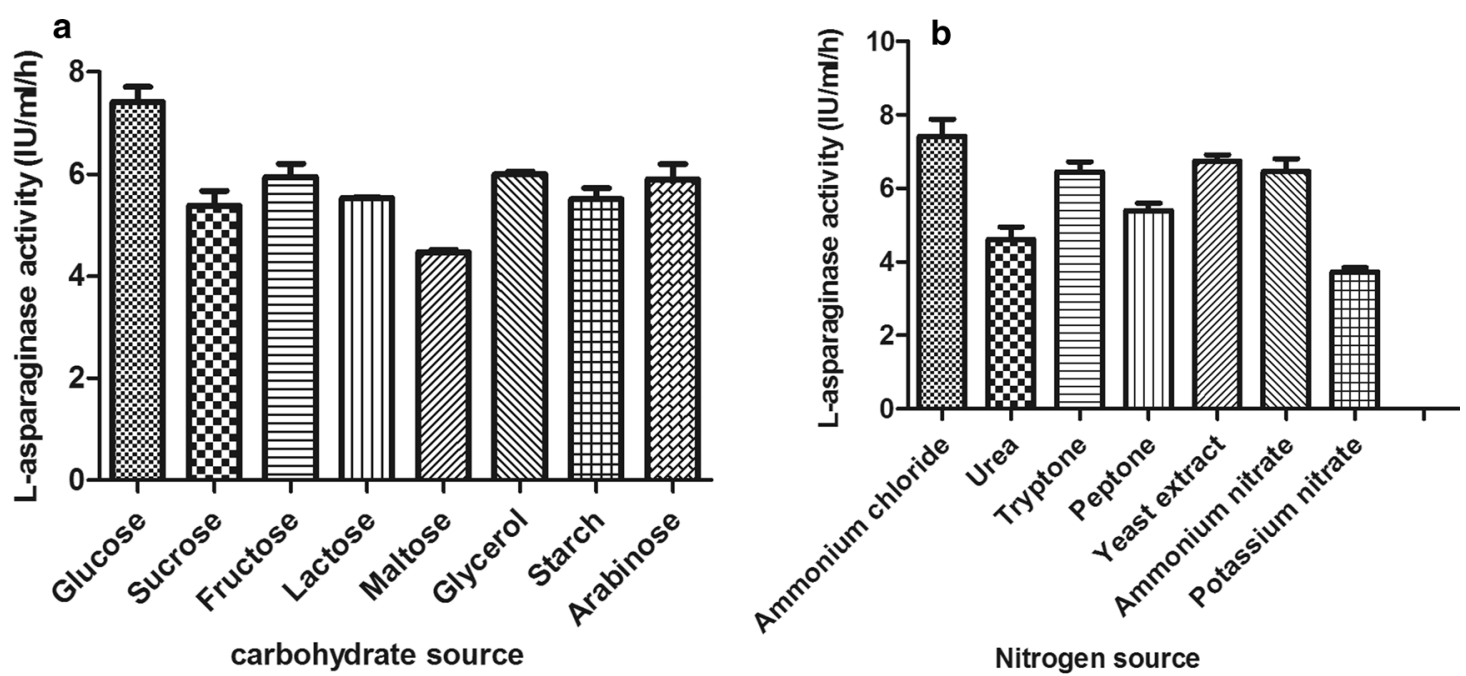

Nitrogen source
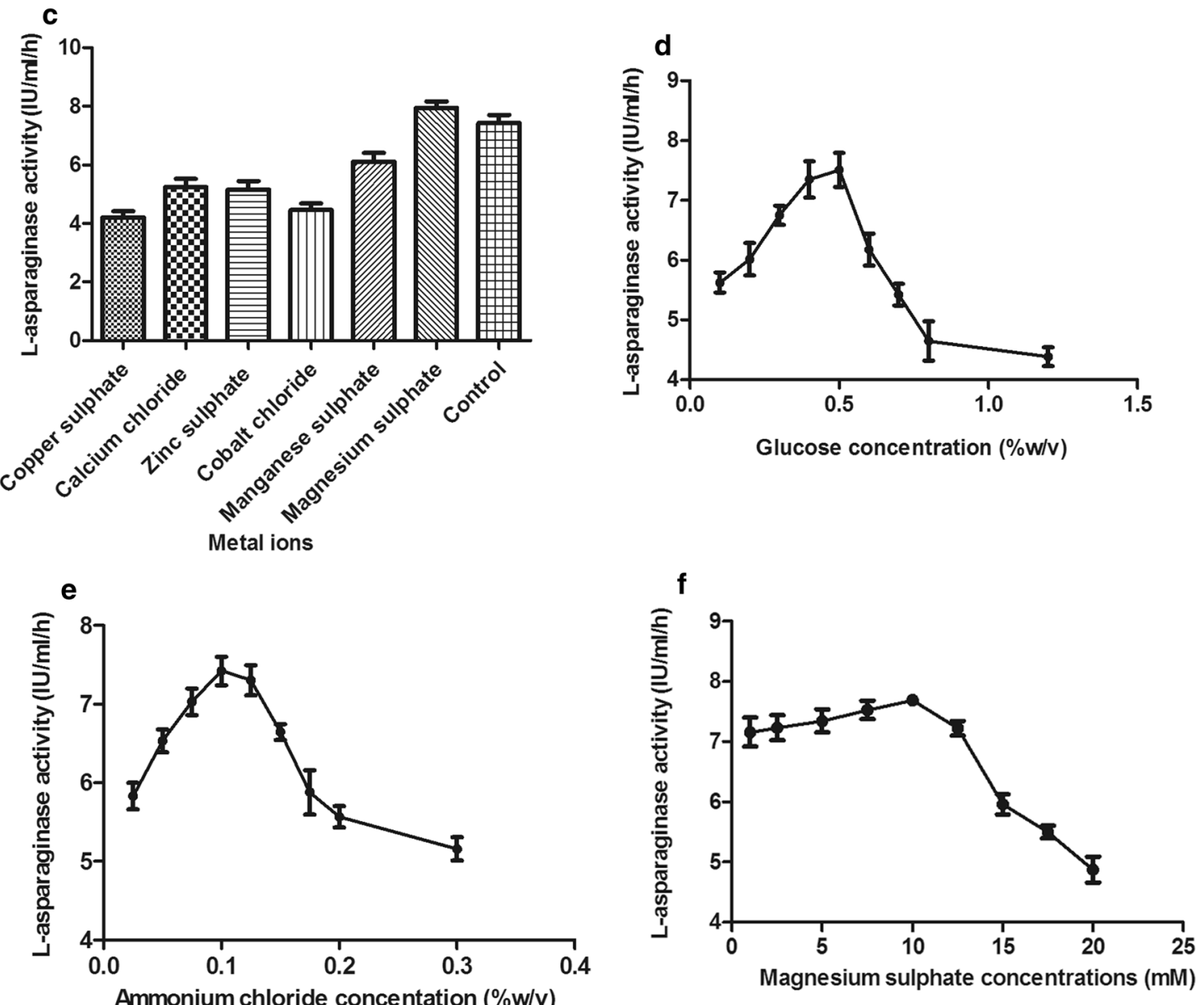

Fig. 7 Effect of different carbon sources (a), nitrogen sources (b), metal ions (c) and different concentrations of glucose (d), ammonium chloride (e) and magnesium sulphate (f) on L-asparaginase production by Bacillus licheniformis mutant strain. The enzyme productivity was expressed in terms of catalytic activity 
$70{ }^{\circ} \mathrm{C}$ for $30 \mathrm{~min}$. This stability level suits its use medically since higher thermal stability is usually required for industrial enzymes. Our results agreed with a previous report (Elshafei et al. 2012), where L-asparaginase produced from Penicillium brevicompactum was stable over wide range of temperatures till $70{ }^{\circ} \mathrm{C}$. The activity of the enzyme preparation of the test isolate increased gradually over the range of 20 up to $35^{\circ} \mathrm{C}$ and decreased at $45{ }^{\circ} \mathrm{C}$ by $27.7 \%$. It showed maximum activity at $40{ }^{\circ} \mathrm{C}$. The optimum alkaline $\mathrm{pH}$ of the enzyme is attributed to that the aspartate liberated by asparagine hydrolysis has lower affinity to the active catalytic site of the enzyme. This enables more binding of asparagine to the enzyme. On the other hand at acidic $\mathrm{pH}$ the breakdown of asparagine by the enzyme results in the production of aspartic acid which has high affinity to the enzyme catalytic site, disabling the binding of asparagine to the enzyme (ElSabbagh et al. 2013). The same results were recorded by other researchers (Elshafei et al. 2012; El-Sabbagh et al. 2013) who found the maximum enzyme activity from Streptomyces halstedii and Penicillium brevicompactum at $\mathrm{pH}$ 8.0, while others reported the maximum activity from B. licheniformis and Streptomyces gulbargensis at pH 9.0 (Amena et al. 2010; Mahajan et al. 2014). Water molecules play a significant role in protein's biological function by attaching to the surface and entering into the inner part of protein molecules (Persson and Halle 2008). When water activity is affected by drastic conditions, like extreme temperature, $\mathrm{pH}$ or high salinity, normally water may limit the enzyme activity. In our study, L-asparaginase showed increased activity (about $48.0 \%$ ) at $500 \mathrm{mM}$ sodium chloride concentration. The increase in the activity can be explained as that salinity may stimulate loop flexibility in the structure of the enzyme that can be more involved in enzymatic activity. Halophilic enzymes have high negative charges so can be easily dissociated and become more flexible in the presence of sodium chloride (Han et al. 2014). The current results agree with that of some researches (Elshafei et al. 2012; Dash et al. 2016; Shechtman 2013; Han et al. 2014). A gradual increase in the enzyme activity was reported by increasing asparagine concentration followed by slight decrease in the activity at higher concentration. Similar results were also reported previously (El-Mched et al. 2015). This finding may be attributed to the saturation of the active enzymatic sites by the substrate. Metal ions acts as cofactor for binding at the catalytic site of the enzyme. Zinc and iron slightly increased the activity which is the same as reported by some investigators (Han et al. 2014) but not affected by nickel, copper and cobalt as mentioned by others (Moorthy et al. 2010). Conversely, it disagreed with what was reported previously (El-Sabbagh et al. 2013) where zinc inhibited the activity of L-asparaginase.
Gamma ray, used in strain improvement, it causes mutation through breakage of single and double stranded DNA resulting structural changes or oxidation (Huma et al. 2012). In this study, it improved L-asparaginase production by 1.4 folds compared to the wild type strain. Many researches supported the use of gamma radiation in increasing the enzymes production (Hoe et al. 2016; Huma et al. 2012; Hyster and Ward 2016; Diep et al. 2017).

The RSM includes a group of statistical and mathematical techniques for development of a sufficient relationship between a response of interest and number of variables through conducting some preliminary studies to determine the optimum range for each factor to be used in RSM. Maximum L-asparaginase production occurred at $37{ }^{\circ} \mathrm{C}$. Any decrease or increase from the optimum temperature slows down the metabolic activity of the enzymes as reported by some investigators (El-Hefnawy et al. 2015; Jayaramu et al. 2010). However, Prakasham et al. reported progressive increase in activity by increasing temperature and optimum temperature attained at $39{ }^{\circ} \mathrm{C}$ (Prakasham et al. 2007). Our results agreed with what was reported previously (Bahrani 2016). Optimum pH was 7 followed by slight decline in productivity at higher $\mathrm{pH}$ values, this may be due to partial enzyme denaturation in response to dissociation of ionizable groups of the enzyme. A significant decrease in enzyme productivity at low $\mathrm{pH}$ may be attributed to inhibition of substrate binding to the enzyme as a result of change in the properties and shape of the enzyme and/ or the substrate (El-Hefnawy et al. 2015). This agreed with some studies (Kavitha and Vijayalakshmi 2010; Bahrani 2016) but also differed with others (Pradhan and Dash 2013; Jayaramu et al. 2010; Prakasham et al. 2007), where their optimum reported $\mathrm{pHs}$ were $6.5,7.5$ and 6 , respectively. The importance of incubation time was recorded by some researchers (Pradhan and Dash 2013; Maysa et al. 2010), who mentioned similar results to that of the current study. At prolonged incubation time the production level started to decrease, long incubation time can lead to degradation of the enzyme by the proteolytic enzymes, and also it causes depletion of medium components or production of some enzyme inhibitors in the medium. The shorter incubation time is cost effective and reduces the chance of the enzyme decomposition (El-Hefnawy et al. 2015). On contrary, other studies demonstrated diverse results; the optimum incubation time for Emericella nidulans and Stenotrophomonas maltophilia was $48 \mathrm{~h}$ (El-Mched et al. 2014; Jayaramu et al. 2010), $72 \mathrm{~h}$ for Streptomyces tendae and Penicillium oxalicum (Kavitha and Vijayalakshmi 2010; El-Hefnawy et al. 2015). Owing to the agitation influence on the availability of the oxygen and nutrient in the medium 
(Sooch and Kauldhar 2013), the increase in the agitation rate helps in mixing of the nutrients which enhance its absorption by the microorganisms (Pansuriya and Singhal 2011), and the decrease in the production at higher agitation rate may be attributed to the shear stress on the bacterial cells (Sooch and Kauldhar 2013). Other published reports revealed higher enzyme production at $220 \mathrm{rpm}$ (Bahrani 2016) and at $150 \mathrm{rpm}$ (Sooch and Kauldhar 2013).

The RSM model has a second order polynomial equation that relates the square root values of $\mathrm{L}$-asparaginase activity to the tested variables. A model of high significance was obtained, as evident from the Fisher's F-test, with a very low probability value $(\mathrm{P}$ model $>\mathrm{F})=0.0001$. The goodness of fit of the model was checked by several statistical criteria. The high determination coefficient indicates that only $4.91 \%$ of the total variation is not explained by the model. The lack of fit F-value of 19.23 and p-value of 0.0504 imply that lack of fit is not significant relative to the pure error and the model accordingly shows excellent fit. The adjusted $\mathrm{R}^{2}$ meant that the model can explain $90.92 \%$ of the variability if the sample was a subset of the population other than the studied sample, its value is always lower than the $R^{2}$. The Predicted $R^{2}$ of the model explained that $76.0 \%$ of observations other than the fed in data can be correctly anticipated by the model and the model has high predictive abilities (Frost 2013). The model adequately compares the range of the predicted values at the design points to the average prediction error. Ratios greater than 4 indicate adequate model discrimination and it can navigate the design space. Reliability is defined as the overall consistency of measure. Its index measure is the coefficient of variation $(\mathrm{CV})$ which is the ratio of the standard deviation to the mean. The lower the value of the $\mathrm{CV}$, the more reliable and precise the model is considered. It implies high reliability and excellent precision (Shechtman 2013). All of these considerations indicate the adequacy of the established regression model.

The results of the $3 \mathrm{D}$ response surface and $2 \mathrm{D}$ contour plots revealed that increasing the medium $\mathrm{pH}$ to 7.5 , shifting the incubation temperature to $40{ }^{\circ} \mathrm{C}$, increasing the agitation rate to $190 \mathrm{rpm}$ and decreasing the incubation time to $18 \mathrm{~h}$ increase $\mathrm{L}$-asparaginase productivity by the test isolate.

Regarding media components, glucose has been responsible for bacterial catabolic repression as it is considered as a quickly metabolized substance but in some cases its incorporation help in enhancing the metabolite production. In our study, glucose increased L-asparaginase productivity. Glucose may provide a positive effect on enhancing L-asparaginase biosynthesis (Baskar and Renganathan 2011; El-Hefnawy et al. 2015). Similarly, glucose enhanced L-asparaginase productivity from Aeromonas sp., and Aspergillus terreus (Amena et al. 2010; Baskar and Renganathan 2011; El-Hefnawy et al. 2015; Doriya and Kumar 2016; Varalakshmi and Raju 2013), while sucrose and sorbitol increased the enzyme biosynthesis from Streptomyces tendae (Kavitha and Vijayalakshmi 2010) and lactose in case of E. coli (Bahrani 2016). Nitrogen sources help in the production of nucleic acid, protein and cell wall and it affects enzymes production. Ammonium chloride was the best source and it was mentioned in many reports (Baskar and Renganathan 2009; Meghavarnam and Janakiraman 2015; Hymavathi et al. 2010). The optimum concentration for maximum production was $0.1 \% \mathrm{w} / \mathrm{v}$ in our study and it was $0.5 \%$ and $2 \% \mathrm{w} / \mathrm{v}$ in other studies (Kavitha and Vijayalakshmi 2010; Amena et al. 2010; El-Hefnawy et al. 2015). Magnesium increased L-asparaginase production, as published previously. In this study, $10 \mathrm{mM}$ magnesium $(1.2 \% \mathrm{w} / \mathrm{v})$ proved to be optimum concentration for $\mathrm{L}$-asparaginase production and a significant decrease in enzyme production occurred at higher concentrations as magnesium may interfere with the bacterial cell division at high concentrations. Based on the above discussion, Bacillus licheniformis revealed a promising L-asparaginase production for different applications. Model-based optimization for enzyme production was established in this study and it can be exploited for enzyme production at a large scale level.

\section{Additional file}

Additional file 1: Table S1. Levels of reaction conditions of process parameters as independent variables studied in RSM experimental design for optimization of $\mathrm{L}$-asparaginase production by the selected test mutant. Table S2. Experiments that were deduced by the RSM experimental design and performed for L-asparaginase production by the mutant. Table S3. Pairwise distances among L-asparaginases of bacterial species presented in the phylogenetic tree shown in Fig. 1. Table S4. Pairwise distances among L-asparaginases of Bacillus licheniformis, E. coli and Erwinia chrysanthemi presented in the phylogenetic tree shown in Figure 2. Table S5. ANOVA of the quadratic model for the process parameters optimization of L-asparaginase productivity by Bacillus licheniformis mutant using Box-Behnken central composite design.

\section{Authors' contributions}

The authors contributed to the work done in the manuscript as follows: NAA: Conducted the experimental work, summarized the data, wrote the draft of the manuscript. WFE: Shared in design of experiments, analyzed and interpreted the data, revised the manuscript. MMR: Shared in the design and supervised the laboratory experiments, helped in draft writing of the manuscript and data analysis. MMA: Put the work idea, performed the bioinformatics analysis, analyzed and interpreted the data and revised the manuscript. All authors read and approved the final manuscript.

\section{Author details}

${ }^{1}$ Department of Microbiology and Immunology, Faculty of Pharmaceutical Sciences and Pharmaceutical Industries, Future University, Cairo, Egypt. ${ }^{2}$ Department of Microbiology and Immunology, Faculty of Pharmacy, Ain Shams University, African Union Organization St. Abbassia, Cairo 11566, Egypt. 
${ }^{3}$ Department of Microbiology and Immunology, School of Pharmacy \& Pharmaceutical Industries, Badr University in Cairo (BUC), Entertainment Area, Badr, Cairo, Egypt.

\section{Acknowledgements}

The authors would like to thank Dr. Amal Emad and Dr. Nouran Elleboudy for their professional support in genetic based identification and model based optimization, respectively.

\section{Competing interests}

The authors declare that they have no competing interests.

\section{Availability of data and materials}

Please contact author for data request.

\section{Consent for publication}

Not applicable.

\section{Ethics approval and consent to participate}

This article does not contain any studies with human participants or animals performed by any of the authors.

\section{Funding}

Not applicable.

\section{Publisher's Note}

Springer Nature remains neutral with regard to jurisdictional claims in published maps and institutional affiliations.

Received: 17 October 2018 Accepted: 8 February 2019

Published online: 21 March 2019

\section{References}

Adinarayana K, Ellaiah P (2002) Response surface optimization of the critical medium components for the production of alkaline protease by a newly isolated Bacillus sp. J Pharm Pharm Sci 5(3):272-278

Amena S, Vishalakshi N, Prabhakar M, Dayanand A, Lingappa K (2010) Production, purification and characterization of L-asparaginase from Streptomyces gulbargensis. Braz J Microbiol 41 (1):173-178

Anbu P, Gopinath SCB, Chaulagain BP, Lakshmipriya T (2013) Microbial enzymes and their applications in industries and medicine. Biomed Res Int. 2017:2195808

Bahrani MH (2016) Study the optimum parameters for production of cloned L-asparaginase type I by Escherichia coli. Int J Curr Microbiol App Sci 5(8):479-485

Bansal S, Srivastava A, Mukherjee G, Pandey R, Verma AK, Mishra P, Kundu B (2012) Hyperthermophilic asparaginase mutants with enhanced substrate affinity and antineoplastic activity: structural insights on their mechanism of action. FASEB J 26(3):1161-1171

Barry E, DeAngelo DJ, Neuberg D, Stevenson K, Loh ML, Asselin BL, Barr RD, Clavell LA, Hurwitz CA, Moghrabi A (2007) Favorable outcome for adolescents with acute lymphoblastic leukemia treated on Dana-Farber Cancer Institute acute lymphoblastic leukemia consortium protocols. J Clin Oncol 25(7):813-819

Baskar G, Renganathan S (2009) Evaluation and screening of nitrogen source for L-asparaginase production by Aspergillus terreus MTCC 1782 using latin square design. Res J Math Stat 1(2):55-58

Baskar G, Renganathan S (2011) Production of L-asparaginase from natural substrates by Aspergillus terreus MTCC 1782: optimization of carbon source and operating conditions. Int J Chem React Eng. https://doi. org/10.1515/1542-6580.2479

Batool T, Makky EA, Jalal M, Yusoff MM (2016) A comprehensive review on L-asparaginase and its applications. Appl Biochem Biotechnol 178(5):900-923

Biswaprakash Pradhan S, Dash SS (2013) Optimization of some physical and nutritional parameters for the production of $\mathrm{L}$-asparaginase by isolated thermophilic Pseudomonas aeruginosa strain F1. Biosci Biotech Res Asia 10:389-395
Bodey GP, Hewlett JS, Coltman CA, Rodriguez V, Freireich EJ (1974) Therapy of adult acute leukemia with daunorubicin and L-asparaginase. Cancer 33(3):626-630

Boyse EA, Old LJ, Campbell HA, Mashburn LT (1967) Suppression of murine Leukemias By L-asparaginase: incidence of sensitivity among leukemias of various types: comparative inhibitory activities of guinea pig serum L-asparaginase and Escherichia coli L-asparaginase. J Exp Med 125(1):17-31

Campbell HA, Mashburn LT (1969) L-Asparaginase EC-2 from Escherichia coli Some substrate specificity characteristics. Biochemistry 8(9):3768-3775

Cavanna M, Celle G, Dodero M, Picciotto A, Pannacciulli I, Brambilla G (1976) Comparative experimental evaluation of immunodepressive and toxic effects of L-asparaginase (NSC-109229) from Escherichia coli and from Erwinia carotovora. CancerTreatRep 60(3):255-257

Dash C, Mohapatra SB, Maiti PK (2016) Optimization, purification, and characterization of L-asparaginase from Actinomycetales bacterium BkSoiiA. Prep Biochem Biotechnol 46(1):1-7

Deokar VD, Vetal MD, Rodrigues L (2010) Production of intracellular L-asparaginase from Erwinia carotovora and its statistical optimization using response surface methodology (RSM). Int J Chem Sci 1:25-36

Diep TB, Thom NT, Sang HD, Thao HP, Van Binh N, Thuan TB, Lan VTH, Quynh TM (2017) Screening streptomycin resistant mutations from gamma ray irradiated Bacillus subtilis B5 for selection of potential mutants with high production of protease. VNU J Sci Nat Sci Technol 32(1S):16-19

Doriya K, Kumar DS (2016) Isolation and screening of L-asparaginase free of glutaminase and urease from fungal sp. Biotech 6(2):239

El-Hefnawy MAA, Attia M, El-Hofy ME, Ali SMA (2015) Optimization Production of $\mathrm{L}$ asparaginase by locally isolated filamentous fungi from Egypt. Curr Sci Int 4(3):330-341

El-Mched F, Olama Z, Holail H (2014) Optimization of the enviromental factors affecting Stenotrophomonas SSPFZL-asparaginase production. Int Res J Nat Sci 2(3):1-16

El-Mched F, Olama Z, Holail H (2015) Purification and characterization of L-asparaginase from soil isolate under solid state fermentation. Int Res Pure Appl Phys. 3(1):30-43

El-Sabbagh SM, El-Batanony SM, Salem TA (2013) L-Asparaginase produced by Streptomyces strain isolated from Egyptian soil: purification, characterization and evaluation of its anti-tumor. Afr J Microbiol Res 7(50):5677-5686

Elshafei AM, Hassan MM, Abouzeid MA-E, Mahmoud DA, Elghonemy DH (2012) Purification, characterization and antitumor activity of L-asparaginase from Penicillium brevicompactum NRC 829. Br Microbiol Res 2(3):2231

Frost J (2013) Multiple regression analysis: Use adjusted R-squared and predicted R-squared to include the correct number of variables. The Minitab Blog, http://blog.minitab.com/blog/adventures-in-statistics/ multiple-regessionanalysis-use-adjusted-r-squared-and-predicted-r-squar ed-to-include-the-correctnumber-of-variables. June, 30, 2015

Gopinath SC, Anbu P, Lakshmipriya T, Hilda A (2013) Strategies to characterize fungal lipases for applications in medicine and dairy industry. Biomed Res Int 2013:1-2

Han S, Jung J, Park W (2014) Biochemical characterization of L-asparaginase in $\mathrm{NaCl}$-tolerant Staphylococcus sp. OJ82 isolated from fermented seafood. J Microbiol Biotechnol 24(8):1096-1104

Hoe PCK, Khairuddin AR, Halimi MS (2016) A review on microbial mutagenesis through gamma irradiation for agricultural applications. Jurnal Sains Nuklear Malaysia 28(2):20-29

Huma T, Rashid MH, Javed MR, Ashraf A (2012) Gamma ray mediated mutagenesis of Phialocephala humicola: effect on kinetics and thermodynamics of a-amylase production. Afr J Microbiol Res 6(22):4639-4646

Hymavathi M, Sathish T, Brahmaiah P, Prakasham RS (2010) Impact of carbon and nitrogen sources on $\mathrm{L}$-asparaginase production by isolated Bacillus circulans (MTCC 8574): application of saturated Plackett-Burman design. Chem Biochem Eng Q 24(4):473-480

Hyster TK, Ward TR (2016) Genetic optimization of metalloenzymes: enhancing enzymes for non-natural reactions. Angew Chem Int Ed 55(26):7344-7357

Izadpanah QF, Javadpour S, Malekzadeh K, Tamadoni Jahromi S, Rahimzadeh M (2014) Persian gulf is a bioresource of potent L-asparaginase producing bacteria: isolation \& molecular differentiating. Int J Environ Res 8(3):813-818 
Jain R, Zaidi K, Verma Y, Saxena P (2012) L-asparaginase: a promising enzyme for treatment of acute lymphoblastic leukiemia. People's J Sci Res 5(1):29-35

Jayaramu M, Hemalatha NB, Rajeshwari CP, Siddalingeshwara KG, Mohsin SM Sunil Dutt PLNSN (2010) A novel approach for detection, confirmation and optimization of L-asparaginase from Emericella nidulans. Curr Pharm Res 1(1):20

Jones DT, Taylor WR, Thornton JM (1992) The rapid generation of mutation data matrices from protein sequences. Comput Appl Biosci 8(3):275-282

Joseph B, Rajan SS (2011) L-lysine alpha oxidase from fungi as an anti tumor enzyme agent. Adv Biotechnol 10(8):27-30

Kavitha A, Vijayalakshmi M (2010) Optimization and purifi cation of L-asparaginase produced by Streptomyces tendae TK-VL_333. Z Naturforsch C 65(7-8):528-531

Kolaskar AS, Tongaonkar PC (1990) A semi-empirical method for prediction of antigenic determinants on protein antigens. FEBS Lett 276(1-2):172-174

Krishnapura PR, Belur PD, Subramanya S (2016) A critical review on properties and applications of microbial L-asparaginases. Crit Rev Microbiol 42(5):720-737

Kumar S, Stecher G, Michael L, Knyaz C, Tamura K (2018) MEGA X: molecular evolutionary genetics analysis across computing platforms. Mol Biol Evol 35(6):1547-1549

Lay HN, Ekert H, Colebatch JH (1975) Combination chemotherapy for children with acute lymphocytic leukemia who fail to respond to standard remission induction therapy. Cancer 36(4):1220-1222

Mahajan RV, Saran S, Kameswaran K, Kumar V, Saxena RK (2012) Efficient production of L-asparaginase from Bacillus licheniformis with low-glutaminase activity: optimization, scale up and acrylamide degradation studies. Bioresour Technol 125:11-16

Mahajan RV, Kumar V, Rajendran V, Saran S, Ghosh PC, Saxena RK (2014) Purification and characterization of a novel and robust L-asparaginase having low-glutaminase activity from Bacillus licheniformis: in vitro evaluation of anti-cancerous properties. PLoS ONE 9(6):e99037

Mashburn LT, Wriston JC (1963) Tumor inhibitory effect of L-asparaginase. Biochem Biophys Res Commun 12(1):50-55

Maysa EM, Amira M, Gamal E, Sanaa T, Sayed El (2010) Production, immobilization and anti-tumor activity of L-asparaginase of Bacillus sp. R36. J Am Sci 6(8):157-165

Megavarnam AK, Janakiraman S (2015) Optimization of physiological growth conditions for maximal production of L-asparaginase by Fusarium species. Int J Bioassays 4(10):4369-4375
Michalska K, Jaskolski M (2006) Structural aspects of L-asparaginases, their friends and relations. Acta Bio chim Pol 53(4):627

Moorthy V, Ramalingam A, Sumantha A, Shankaranaya RT (2010) Production, purification and characterisation of extracellular L-asparaginase from a soil isolate of Bacillus sp. Afr J Microbiol Res 4(18):1862-1867

Nigam PS (2013) Microbial enzymes with special characteristics for biotechnological applications. Biomolecules 3(3):597-611

Pansuriya RC, Singhal RS (2011) Effects of dissolved oxygen and agitation on production of serratiopeptidase by Serratia marcescens NRRL B-23112 in stirred tank bioreactor and its kinetic modeling. J Microbiol Biotechnol 21(4):430-437

Persson E, Halle B (2008) Cell water dynamics on multiple time scales. Proc Natl Acad Sci USA 105(17):6266-6271

Prakasham RS, Rao CS, Rao RS, Lakshmi GS, Sarma PN (2007) L-asparaginase production by isolated Staphylococcus sp.-6A: design of experiment considering interaction effect for process parameter optimization. J Appl Microbiol 102(5):1382-1391

Roberts J, Prager MD, Bachynsky N (1966) The antitumor activity of Escherichia coli L-asparaginase. Cancer Res 26(10):2213-2217

Sakr MM, Aboulwafa MM, Aboshanab KMA, Hassouna NAH (2014) Screening and preliminary characterization of quenching activities of soil bacillus isolates against acyl homoserine lactones of clinically isolated Pseudomonas aeruginosa. Malays J Microbiol 10:80-91

Seale RB, Flint SH, McQuillan AJ, Bremer PJ (2008) Recovery of spores from thermophilic dairy bacilli and effects of their surface characteristics on attachment to different surfaces. Appl Environ Microbiol 74(3):731-737

Shechtman O (2013) The coefficient of variation as an index of measurement reliability Methods Clin Epidemiol. Springer, Berlin, pp 39-49

Sinha RA, Singh HR, Jha SK (2013) Microbial L-asparaginase: present and future prospective. Int J Innov Res Sci Eng 2(11):7031-7051

Sooch BS, Kauldhar BS (2013) Influence of multiple bioprocess parameters on production of lipase from Pseudomonas sp. BWS-5. Braz Arch Biol Technol 56(5):711-721

Straight PD, Fischbach MA, Walsh CT, Rudner DZ, Kolter R (2007) A singular enzymatic megacomplex from Bacillus subtilis. Proc Natl Acad Sci USA 104(1):305-310

Varalakshmi V, Raju KJ (2013) Optimization of L-asparaginase production by Aspergillus terreus mtcc 1782 using bajra seed flour under solid state fermentation. Int J Res Eng Technol 2(09):121-129

\section{Submit your manuscript to a SpringerOpen ${ }^{\circ}$ journal and benefit from:}

- Convenient online submission

- Rigorous peer review

- Open access: articles freely available online

- High visibility within the field

- Retaining the copyright to your article

Submit your next manuscript at springeropen.com 